\title{
Review
}

\section{Protein and Imaging Biomarkers in the Eye for Early Detection of Alzheimer's Disease}

\author{
Shaunt Fereshetian ${ }^{\mathrm{a}}$, Joshua S. Agranat ${ }^{\mathrm{a}, \mathrm{b}}$, Nicole Siegel ${ }^{\mathrm{a}, \mathrm{b}}$, Steven Ness $^{\mathrm{a}, \mathrm{b}}$, \\ Thor D. Stein ${ }^{\mathrm{c}, \mathrm{d}, \mathrm{e}, \mathrm{f}}$ and Manju L. Subramanian ${ }^{\mathrm{a}, \mathrm{b}, *}$

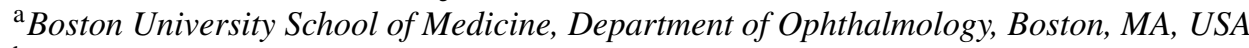 \\ ${ }^{\mathrm{b}}$ Boston Medical Center, Boston, MA, USA \\ ${ }^{\mathrm{c}}$ Boston University Alzheimer's Disease and CTE Center, Boston University School of Medicine, Boston, \\ MA, USA \\ ${ }^{\mathrm{d}}$ Department of Pathology and Laboratory Medicine, Boston University School of Medicine, Boston, MA, USA \\ ${ }^{\mathrm{e}}$ VA Boston Healthcare System, Boston, MA, USA \\ ${ }^{\mathrm{f}}$ Department of Veterans Affairs Medical Center, Bedford, MA, USA
}

Accepted 26 March 2021

Pre-press 19 April 2021

\begin{abstract}
Alzheimer's disease (AD) is one of the most common causes of dementia worldwide. Although no formal curative therapy exists for the treatment of $\mathrm{AD}$, considerable research has been performed to identify biomarkers for early detection of this disease, and thus improved subsequent management. Given that the eye can be examined and imaged non-invasively with relative ease, it has emerged as an exciting area of research for evidence of biomarkers and to aid in the early diagnosis of AD. This review explores the current understanding of both protein and retinal imaging biomarkers in the eye. Herein, primary findings in the literature regarding $\mathrm{AD}$ biomarkers associated with the lens, retina, and other ocular structures are reviewed.
\end{abstract}

Keywords: Alzheimer's disease, amyloid, cataract, crystalline, eye, lens, retina, vitreous

\section{INTRODUCTION}

Alzheimer's disease (AD) is a common neurodegenerative disorder of older adults and a leading global cause of dementia [1,2]. It is estimated that among patients over age 70, roughly 1 in 10 experience substantial memory loss, with more than half of all cases attributable to $\mathrm{AD}$ [1]. The median cost to care for a patient with AD is believed to be in excess of 50,000 United States Dollars (USD) per individual, annually [1]. According to the Alzheimer's Association, government sponsored health care is expected to

\footnotetext{
${ }^{*}$ Correspondence to: Manju Subramanian, MD, Boston University School of Medicine, 85 East Concord Street, 8th Floor, Boston, MA 02118, USA. Tel.: +1 617638 4552; E-mail: Manju.Subramanian@bmc.org.
}

spend over 200 billion USD caring for those suffering from $\mathrm{AD}$ and dementia [3]. AD involves progressive non-reversible neuronal and synaptic degeneration throughout the cerebral cortex. Characteristic microscopic features are accumulation of amyloid plaques and neurofibrillary tangles [4]. Several theories have been proposed to explain the pathophysiology of AD including the amyloid propagation hypothesis [5] as well as the tau hypothesis [6]; however, the exact mechanism of action has not been fully elucidated. Currently, AD is a clinical diagnosis based on symptoms and neuropsychological testing; however, early detection via imaging and measurements of protein biomarkers is an active area of investigation, with the ultimate goal of detecting $\mathrm{AD}$ in its preclinical stages in order to maximize the potential for earlier treatment intervention and improved outcomes. 
The toll of this debilitating neurodegenerative disease on patients and their families has prompted exploration of methods for early detection via the use of biomarkers. Researchers have assessed the role that imaging with magnetic resonance (MRI) or positron emission tomography (PET) can play; however, the cost of these imaging modalities limits them as a diagnostic screening tool. Cerebrospinal fluid (CSF) biomarkers can play a role in diagnosing AD at earlier stages but are also limited by cost and their invasive nature. The use of blood to detect biomarkers such as neurofilament light chain (NfL), amyloid- $\beta$ $(\mathrm{A} \beta)_{42 / 40}$ ratio, and phosphorylated tau (p-tau)181 has the advantage of being relatively inexpensive and minimally invasive as a test, and recent studies show they may be clinically meaningful.

Over the last 20 years, the eye has emerged as a target of efforts geared toward early detection, as the eye is an extension of the central nervous system and offers the opportunity for non-invasive and multi-modal evaluation for early biomarkers of AD. Moreover, eye disease shares risk factors with $\mathrm{AD}$ and may therefore represent a vulnerable population deserving of additional screening [7-10]. This article is a review of biomarkers for early AD diagnosis that include promising protein and image-based intraocular targets. The focus on both proteins and biomarkers obtained by noninvasive imaging makes this review unique from prior reviews which have primarily emphasized either one or the other, and by doing so we offer a comprehensive assessment to address the possible applicability of both sources from the eye as distinct and potentially synergistic markers for early $\mathrm{AD}$ detection.

\section{BRIEF REVIEW AND CURRENT STATE OF BIOMARKER RESEARCH}

The detection of AD in patients through distinct biomarkers is an area of active study. Researchers have explored the role that noninvasive and invasive image-based modalities such as functional, structural, and amyloid PET imaging could play in identifying unique changes to the brain specific to $A D$ [11-13]. Several studies have also analyzed patient serum or CSF samples for clinically meaningful AD biomarkers, often in combination with observed imaging changes [14-17]. It has been shown repeatedly that earlier intervention and therapy can have significant benefits for AD patients, further highlighting the importance and necessity of developing methods to identify biomarkers for early detection of this disease [18, 19].

Currently, some of the most promising and heavily investigated biomarkers for supporting the diagnosis of $A D$ include low CSF levels of $A \beta_{42}$ or $A \beta_{42}: A \beta_{40}$ ratio, amyloid PET imaging, various biomarkers of tau deposition, including increased CSF total tau, and tau PET imaging [20]. In 2018, the NIA-AA issued updated guidelines for diagnostic testing to help researchers form a biological, biomarker-based definition of $\mathrm{AD}$, framed within the ATN classification system established by Jack et al. in 2016 [21]. A signifies changes on amyloid PET imaging and CSF levels of $A \beta_{1-42}, T$ - indicates biomarkers of tau, including tau PET or CSF p-tau, while N stands for neurodegeneration as reflected by CSF total tau (t-tau), F-2-fluoro-2-deoxy-d-glucose PET (FDGPET), and atrophy on magnetic resonance imaging (MRI). Ultimately, the recommendations put forth by the NIA-AA were for research purposes with the eventual goal of refining clinical practice. The authors deliberately did not include specific recommendations but created a general framework for better understanding the sequence of events that leads to $\mathrm{AD}$, assisting with potential treatments and drug therapy [22], and creating a "common language" [23].

To date, there remains no clinical guidelines or recommendations on utilizing biomarker testing as part of routine screening or for early diagnosis of $\mathrm{AD}$ prior to symptom onset. Additionally, while the methods utilizing imaging modalities and CSF sampling have shown considerable promise in aiding probable or suspected clinical diagnosis, these tests are expensive, may involve radiation exposure, and are often invasive. The identification of cheaper, minimally-invasive methods for detecting both known biomarkers and new biomarkers in other organs and fluids remains a goal for researchers in the field.

\section{THE HUMAN CRYSTALLINE LENS}

The optically clear crystalline lens is located in the anterior segment of the eye, posterior to the iris [24]. Via accommodation, the lens, in tandem with the cornea, refract light onto the retina beginning the process of visual perception. The lens fibers are long, normally transparent cells that are known to accumulate misfolded protein aggregates over time [25-27]. The development of cataract is a common clinical condition that occurs with increasing age and can lead to vision loss over time. The removal of the lens 
from cataract formation is the most common surgical procedure in the US, and each year approximately 3 million people in the US undergo cataract surgery.

In 2003, Goldstein et al. were among the first to demonstrate amyloid- $\beta$ protein precursor (A $\beta P P)$ and $A \beta$ deposition was detectable in cadaveric human lens samples of patients with diagnosed AD. They reported, that via immunohistochemistry (using monoclonal antibodies against $\mathrm{A} \beta$, specifically $4 \mathrm{G} 8 / \beta \mathrm{A} 4)$ and confirmed through tryptic digest, tandem liquid chromatography/mass spectrometry, that $A \beta$ deposition could be identified at the level of the lens. The authors also reported a characteristic and distinct cortical cataract opacification in known AD patients, and additionally concluded that amyloid deposition was identifiable in the human lens as in the brain and that the molecular machinery necessary for the accumulation of $A \beta$ was present in the lens itself, and not derived from the brain [28].

In 2010, Moncaster et al. expanded on their initial findings to analyze the lenses of patients suffering from trisomy 21, Down syndrome (DS) [29]. Chromosome 21 contains the gene encoding for A $\beta P P$ [30], predisposing DS patients to accumulate amyloid deposition within the brain, developing dementia in a process much akin to AD [31]. Those suffering from this condition typically experience symptoms and onset of dementia and $\mathrm{AD}$ at an earlier age, compared to healthy patients [32]. Moncaster et al. utilized peptide sequencing, immunoblot analyses, and ELISA to demonstrate accumulation of $A \beta$ amyloid aggregates within the lens. Additionally, the authors indicated that staining and slit lamp examination showed the same characteristic supranuclear opacifications previously described [29].

A subsequent study in 2012, by the same group of authors, aimed to identify genetic factors that linked the formation of age-related cataracts to AD. Jun et al. examined lens opacity imaging from 1,249 patients from the Framingham Eye Offspring Study and genome wide association studies and identified a statistically significant correlation of cortical cataracts with AD-related brain changes and suggested that genetic variations in Catenin Delta 2 gene (gene associated with both brain and eye development) may represent a link in cortical cataract formation and $\mathrm{AD}$ associated changes to the brain, identified by MRI [33].

A 2013 study by Kerbage et al. explored the use of a combination topical compound that binds to aggregated $A \beta$ peptide and laser scanning device, called SAPPHIRE system, to examine in vivo human lenses and found a 2-fold increase in fluorescent signature in the thickest supranuclear region in their AD patients compared to controls [34]. The authors conducted a similar study in 2015 , showing a statistically significant difference in fluorescent signature via the use of the fluorescent ligand eye scanning techniques and demonstrated that lens findings significantly correlated with florbetapir F18 PET amyloid brain analysis and imaging findings [35].

Given the safety, relative ease, and multitude of non-invasive techniques to examine the lens, the Goldstein, Moncaster, Jun, and Kerbage studies have sparked considerable interest from the scientific community to delve further into identifying neuropathological changes associated with $\mathrm{AD}$ in the lens. However, subsequent studies exploring their findings presented inconsistent results.

A study published in 2013 in Experimental Eye Research, by authors Michael et al., was unable to replicate the findings from Goldstein and Moncaster. The authors, analyzing the brains and lenses of 21 patients with $\mathrm{AD}$ and 15 without, could not successfully identify $A \beta$ deposition in any of the cadaveric lenses from their study [36] nor the characteristic supranuclear opacification among their donor samples. The authors performed a follow up study in 2014, utilizing confocal Raman micro-spectroscopy and were unable to reveal the presence of $A \beta$ in the cataracts of known AD patients [37]. In 2014, authors Ho et al. were unable to detect any $A \beta$ deposition in the crystalline lens or retina of eleven neuropathologically diagnosed AD patients, four DS patients, and six age-matched controls [38]. In a 2017 study published in the Journal of Neuropathology and Experimental Neurology, Williams et al. were unable to identify evidence of deposits in any part of the globe after immunostaining (monoclonal antibody 6F/3D) [39].

Both the Ho article from 2014 and the Williams article from 2017 examined postmortem eyes of known AD patients for evidence of inclusions, or proteinaceous deposits of other known AD biomarkers such as tau. Neither study was able to demonstrate deposits of tau at any level or compartment in the eye as well. It should also be noted that the original articles from Goldstein and Moncaster asserted evidence of $A \beta$ deposition at the lens and did not directly address deposition of other aggregates such as tau that are historically linked to $\mathrm{AD}$ in the brain [6, 40-42] (See Table 1 for summary of articles).

It is unclear why recent studies have been unable to replicate the findings of Goldstein and Moncaster. Some of the proposed theories include discrepancies 
Table 1

Studies looking for evidence of $A \beta$ in the lens

\begin{tabular}{lc}
\hline Title & Year, Authors [R \\
\hline $\begin{array}{l}\text { Cytosolic } \beta \text {-amyloid deposition and } \\
\text { supranuclear cataracts in lenses from }\end{array}$ & 2003 , Goldstein \\
people with Alzheimer's disease. & et al. [28] \\
& \\
Alzheimer's disease amyloid- $\beta$ links lens & 2010, Moncaster \\
and brain pathology in Down syndrome. & et al. [29]
\end{tabular}

$\delta$-Catenin is genetically and biologically associated with cortical cataract and future Alzheimer-related structural and functional brain changes

Alzheimer's disease diagnosis by detecting exogenous fluorescent signal of ligand bound to Beta amyloid in the lens of human eye: an exploratory study

Detection of amyloid $\beta$ signature in the lens and its correlation in the brain to aid in the diagnosis of Alzheimer's disease

\author{
Absence of beta-amyloid in cortical \\ cataracts of donors with and without \\ Alzheimer's disease
}

\begin{abstract}
Absence of amyloid-beta in lenses of Alzheimer patients: a confocal Raman microspectroscopic study
\end{abstract}

Beta-amyloid, phospho-tau and alpha-synuclein deposits similar to those in the brain are not identified in the eyes of Alzheimer's and Parkinson's disease patients

Absence of Alzheimer disease neuropathologic changes in eyes of subjects with Alzheimer disease

\author{
2012, Jun \\ et al. [33] \\ 2013, Kerbage \\ et al. [34] \\ 2015, Kerbage \\ et al. [35]
}

2013, Michael et al. [36]

2014, Michael et al. [37]

2014, Ho et al. [38]

2017, Williams et al. [39]
Significant Finding

Identified $A \beta$ in the supranuclear cortical lens fibers cells of pathology confirmed $\mathrm{AD}$ patients. Identified supranuclear cataracts in lenses of $\mathrm{AD}$ patients compared to controls.

Evaluation of DS lenses showed supranuclear opacification and supranuclear $A \beta$ accumulation identical to the lens pathology identified in AD. Peptide sequencing, immunoblot analysis, and ELISA confirmed the identity and increased accumulation of $\mathrm{A} \beta$ in DS lenses.

Genetic variation in Catenin Delta 2 identified as possible shared link between cortical cataract formation and MRI identified associated changes to the brain, in $\mathrm{AD}$.

Fluorescent ligand and a laser scanning device, SAPPHIRE System, able to detect twofold difference in fluorescence signature in ligand bound $A \beta$ in the supranuclear region of the lenses of AD compared to control patients.

Fluorescent Ligand Eye Scanning (FLES) technique measures significant difference in fluorescence signature from probable $\mathrm{AD}$ patient lenses compared to healthy controls and correlates with F18 amyloid brain imaging use F18.

Neither clinically diagnosed AD or control patient with cortical cataracts stain for $\mathrm{A} \beta$ with Congo red, thioflavin and $\mathrm{A} \beta$ immunohistochemistry staining. Authors conclude an absence of $\mathrm{A} \beta$ in $\mathrm{AD}$ lens or control lens with cortical cataracts.

Utilized confocal Raman microscopy to demonstrate absence of $A \beta$ in lens and ultimately claim cortical lens opacification is not a hallmark of $A \beta$ accumulation in the lenses of $\mathrm{AD}$ patients.

No evidence of amyloid deposits detectable in the lens, retina, or other structures in the eyes of $\mathrm{AD}$ patients. Authors conclude $\mathrm{A} \beta$ either does not deposit in the eye like the brain or is present at lower levels or different forms. Immunohistochemistry for $\mathrm{A} \beta$ fails to demonstrate evidence of inclusions, deposits in any part of the globe in $\mathrm{AD}$ patients. in staining technique, use of monoclonal antibodies with differing epitopes, as well as fixation modality $[36,43]$. The Michael study acknowledges that their cadaveric samples were from patients with a clinical diagnosis of $\mathrm{AD}$ as opposed to the pathological confirmation used in the Goldstein and Moncaster studies [36]. This difference may explain the discrepancy in findings between Goldstein/Moncaster and Michael studies, but fails to apply to the Ho study, as their cadaveric samples had confirmed pathological diagnosis of AD [38]. Additionally, while the Ho, Michael, and Williams studies were unable to demonstrate clear evidence of $A \beta$ in the lens, there are technical and procedural limitations to consider when evaluating their conclusions. One is the technical challenges of fixing, processing, and staining lens material compared to brain tissue. Secondly, the Ho, Michael, and Williams studies do not utilize a secondary analytical method, such as tandem liquid chromatography-mass spectrometry (LC-MS) to confirm their findings of an absence of $A \beta$ in the analyzed tissues. Contrast this to Goldstein, Moncaster, and Jun who utilized tryptic digest sequencing with electrospray ionization LC-tandem mass 
spectrometry to confirm the identity of $A \beta$ in their lens samples. The lack of a specific secondary analytic technique to confirm findings weakens the challenges put forth by the authors in the Ho, Michael, and Williams studies. It should also be noted that confocal Raman microscopy has relatively poor sensitivity as well as low signal specificity when attempting to detect low levels of $A \beta$, as would be expected in the lens [44]. Alternately, LC-MS is specific in identifying a unique tryptic peptide sequence that corresponded to an internal peptide in A $\beta P P$, and sensitive in detecting levels of $A \beta$ at levels several orders of magnitude less than that detectable by Raman microscopy. While Michael et al. attempted to confirm their findings with Raman microscopy, a negative finding utilizing this technique is not definitive evidence of a total absence of A $\beta$. The use of LC-MS in the Goldstein, Moncaster, and Jun studies confirms the presence of $A \beta$ at the lens, and authors Michael, Ho, and Williams do not invalidate this finding. The question that now that remains is, are levels of $A \beta$ in the lens ultimately associated with and potentially predictive of $\mathrm{AD}$ ?

\section{INTRAOCULAR FLUID}

While examination of the anterior segment of the eye (cornea, anterior chamber, lens, ciliary body) has been of interest to researchers looking for early signs of $\mathrm{AD}$, there also have been several studies that have explored the role of eye fluids (aqueous and vitreous humor) and posterior segment (retina and choroid) [45] to determine whether changes might predict the onset of $\mathrm{AD}$. The aqueous humor is a transparent fluid composed primarily of water, amino acids, and electrolytes which fills both the anterior and posterior chambers of the anterior segment of the eye. It serves as a source of micronutrients and immunologic materials for avascular structures such as the cornea and provides intraocular pressure [24]. Studies have looked into sampling the aqueous for evidence of deposition of $A \beta$ [46]. Indeed, authors Goldstein et al. were among the first to demonstrate that beta amyloid, specifically $A \beta_{1-40}$ and $A \beta_{1-42}$, could not only be detected and measured in the aqueous humor, but that levels of such compounds were comparable to that of CSF samples [28].

The vitreous chamber accounts for $80 \%$ of the total volume of the globe [24] and is comprised of an optically clear non-reproducible gelatinous substance composed primarily of water, type II collage, hyaluronan, and glycosyaminoglycans, as well as other proteins. The vitreous serves an important role in supporting the posterior lens and providing shape and structure to the posterior segment of the eye [24]. Several studies have identified AD-associated pathological proteins in both the aqueous and the vitreous humor [46-52]. In 2019 our group published a study that was among the first to find an association of those levels with human cognitive function. Wright et al. sampled the vitreous humor of patients following vitrectomy surgery for eye disease, and found that higher levels of $A \beta_{40}, A \beta_{42}$, and total tau in the vitreous were associated with lower cognitive function, measured by Mini-Mental Status Examination (MMSE) [53]. Notably, these associations were preserved when adjusting for the patients' local eye disease. The findings for total tau were consistent with findings from CSF studies where high CSF levels of tau corresponded with worse cognitive function. On the other hand, $A \beta$ showed an opposite relationship to cognitive function than that observed in the CSF, suggesting that $A \beta$ accumulation in the vitreous follows a different dynamic than that in the CSF where it is inversely related to brain amyloid deposition. Our group subsequently identified NfL in the vitreous humor and reported a positive correlation between $\mathrm{NfL}$ levels and $A \beta_{40}, A \beta_{42}$, and total tau in 77 vitreous samples [54] obtained during surgery from patients with eye disease. The NfL levels noted in the vitreous was adjusted for systemic diseases such as diabetes and was not associated with the patients' clinical eye condition nor APOE genotype. These cumulative findings in the vitreous humor reaffirm other studies suggesting that patients with eye disease are an at-risk population for the development of $\mathrm{AD}$ and suggest that further investigation in patients with eye disease may yield results potentially generalizable to the population at large (Table 2).

\section{RETINA}

The neurosensory retina has been a particular tissue of interest for the detection of amyloid plaque deposition. $\mathrm{AD}$ and brain $\mathrm{A} \beta$ burden has been shown to be associated with $A \beta$ deposits in the retina in animal models [54-59] and in human studies [60, 61]. Several studies have used curcumin, a fluorochrome, to label the presence of $A \beta$ plaques at the retina [62, 63]. Hamaoui et al. reported $A \beta$ in postmortem donor retinal tissue from $\mathrm{AD}$ patients and speculated that retinal $A \beta$ plaques accumulated and progressed at 
Table 2

Studies exploring presence of AD associated biomarkers in the vitreous humor

\begin{tabular}{|c|c|c|}
\hline Title & Year, Authors [Ref] & Significant Finding \\
\hline $\begin{array}{l}\text { Association of cognitive function } \\
\text { with amyloid- } \beta \text { and tau } \\
\text { proteins in the vitreous humor }\end{array}$ & $\begin{array}{c}\text { 2019, Wright } \\
\text { et al. }[53]\end{array}$ & $\begin{array}{l}\text { Poor cognitive function, as determined by } \\
\text { Mini-Mental State Exam, correlated with } \\
\text { lower levels of vitreous } A \beta_{40}, A \beta_{42} \text {, and } \\
\text { tTau. Vitreous biomarkers not associated } \\
\text { with any underlying ophthalmic condition. }\end{array}$ \\
\hline $\begin{array}{l}\text { Neurofilament light chain in the } \\
\text { vitreous humor of the eye }\end{array}$ & $\begin{array}{l}\text { 2020, Subramanian } \\
\text { et al. [54] }\end{array}$ & $\begin{array}{l}\text { Neurofilament light chain identified in } \\
\text { vitreous samples, and significantly } \\
\text { correlated with levels of } A \beta_{40}, A \beta_{42} \text {, and } \\
\text { t-tau. NfL not found to be associated with } \\
\text { any underlying ophthalmic condition. }\end{array}$ \\
\hline
\end{tabular}

the level of the retina before the brain [64]. A 2017 study by Koronyo et al. demonstrated histological evidence of neuronal loss and deposition of $A \beta$ (via the use $12 \mathrm{~F} 4 \mathrm{mAb}$ which targets the $\mathrm{C}$ terminus of $\mathrm{A} \beta_{42}$ ) plaques within the inner layers of the retina of AD patients; this study was important because it was also able to noninvasively image $A \beta$ plaques at the retina, via the use of curcumin staining and retinal imaging in live patients [63]. It should be noted, however, the curcumin binding and fluorescence is not specific for $A \beta$ and not definitive evidence of retinal $A \beta$. Curcumin has been described as binding to dense amyloid structures and not specifically to $A \beta$ peptide [65]. Additionally, several studies previously mentioned in this review have been unable to detect evidence of retinal amyloid deposition via immunostaining [38, 39]. Although these discrepancies may be related to staining technique or methodology, the limited and occasionally confounding data preclude any consensus conclusions on the topic [66].

Histopathological analyses from the late 1980s and early 1990s of cadaveric ocular tissue from AD patients revealed evidence of retinal ganglion cell loss $[67,68]$. Similar methodology has been used to identify evidence of marked thinning of the retinal nerve fiber layer (rNFL), the innermost layer of the retina and an unmyelinated extension of the fibers of the optic nerve, in AD patients compared to controls [69, 70] (Table 3).

While the presence and associations of pathological proteins in eye fluid and retinal tissue is of interest, obtaining a biopsy of vitreous fluid and retina as a source of screening for $\mathrm{AD}$ is not practical because it requires an invasive needle injection or surgical intervention in the operating room. However, there is opportunity to access aqueous humor and lens material in the operative setting for patients undergoing cataract surgery, as it provides us with a mechanism to access eye fluid and tissue for possible screening purposes. Since this is a common procedure, the investigation of pathological proteins for $\mathrm{AD}$ in the eye may be more compelling than lumbar puncture for CSF procurement. Additionally, patients with cataracts and other eye diseases that require surgery are at higher risk for $\mathrm{AD}$ [7-10], therefore, selective screening of the eye during surgery may allow for early detection and follow up in this at-risk group.

\section{NONINVASIVE IMAGING OF THE RETINA}

More recently, current studies investigating the role of the eye in $\mathrm{AD}$ focus on retinal biomarkers imaged by optical coherence tomography (OCT). OCT is a noninvasive photographic test using light waves to take cross sectional images of the retina and macula, providing information on the retina's distinctive cell layers. For example, the rNFL is thinner, retinal volume is reduced, and the choroidal thickness of the eye is reduced in patients with mild cognitive impairment (MCI) and AD compared to cognitively normal (CN) controls [71-81]. A meta-analysis from 2017 by den Haan et al. looked at 25 studies involving 887 patients with $\mathrm{AD}, 216$ with $\mathrm{MCI}$, and $864 \mathrm{CN}$ and demonstrated a statistically significant reduction in mean peripapillary rNFL layer thickness and macular thickness in patients with $\mathrm{MCI}$ and $\mathrm{AD}$ [82].

A 2017 study from the Netherlands compared retinal sublayer thickness, as determined by OCT, to brain MRI of 2124 patients. Mutlu et al. discovered that reduced gray and white matter volume was correlated with thinning of the inner retinal sublayers including the rNFL, the ganglion cell layer, and inner plexiform layer [83]. A similar study by Casaletto et al. used OCT and 3T Brain MRI to compare retinal sublayer thickness with medial temporal lobe volume (MTL) and like Mutlu found that reduction in MTL volume (which they reported as a hallmark of AD) was correlated with thinning of the rNFL as well as total macular and macular ganglion cell layer [84]. 
Table 3

Studies looking at evidence of retinal changes/retinal pathology associated with Alzheimer's disease

\begin{tabular}{l} 
Title \\
\hline Retinal levels of amyloid beta correlate with \\
cerebral levels of amyloid beta in young \\
APPswe/PS1dE9 transgenic mice before onset \\
of Alzheimer's disease \\
Retinal amyloid pathology and proof-of-concept \\
imaging trial in Alzheimer's disease \\
Identification of amyloid plaques in retinas from \\
Alzheimer's patients and noninvasive in vivo \\
optical imaging of retinal plaques in a mouse \\
model
\end{tabular}

Amyloid plaques in retina for diagnosis in Alzheimer's patients: a meta-analysis

Retinal thickness in Alzheimer's disease: A systematic review and meta-analysis

Retinal neurodegeneration and brain MRI markers: the Rotterdam Study

Retinal thinning is uniquely associated with medial temporal lobe atrophy in neurologically normal older adults

Decreased retinal thickness in patients with Alzheimer's disease is correlated with disease severity

Association of retinal nerve fiber layer thinning with current and future cognitive decline: a study using optical coherence tomography

The retinal vessel density can reflect cognitive function in patients with Alzheimer's disease: evidence from optical coherence tomography angiography

Retinal microvasculature dysfunction is associated with Alzheimer's disease and mild cognitive impairment

Retinal microvascular attenuation in mental cognitive impairment and Alzheimer's disease by optical coherence tomography angiography

Retinal nerve fiber layer thinning in Alzheimer's disease: a case-control study in comparison to normal aging, Parkinson's disease, and non-Alzheimer's dementia

Usefulness of peripapillary nerve fiber layer thickness assessed by optical coherence tomography as a biomarker for Alzheimer's disease

Peripapillary retinal nerve fiber layer thickness in patients with Alzheimer's disease: a comparison of eyes of patients with Alzheimer's disease, primary open-angle glaucoma, and preperimetric glaucoma and healthy controls

Significant Finding

Correlation between $\mathrm{A} \beta$ content in retina and cerebrum of APP mice. Curcumin can stain A $\beta$ in the retina but found to suppress levels.

2017, Koronyo et al. [63]

2011, KoronyoHamaoui et al. [64]

2016, Jiang et al. [66]

2017, den Haan et al. [75]

2017, Mutlu et al. [83]

2017, Casaletto et al. [84] 2019, Kim et al. [85]

2018, Ko et al. [86]

2021, Yan et al. [101]

2020, Chua et al. [102]

2020, Wu et al. [103]

2016, Pillai et al. [105]

2018, Sánchez et al. [106]

2019, Zabel et al. [107]
$A \beta$ deposits found at the level of the retina using curcumin fluorochrome. Retinal $\mathrm{A} \beta$ could be imaged in vivo with solid-lipid curcumin and a modified scanning laser ophthalmoscope

Retinal $\mathrm{A} \beta$ plaques identified following systemic administration of curcumin in postmortem eyes of $\mathrm{AD}$ patients. Retinal plaques detectable earlier than in the brain and accumulated with disease progression.

Meta-analysis of 5 studies with small sample sizes fails to identify any conclusion in regard to pathological retinal $A \beta$ detection as a diagnostic tool for AD.

Significant reduction in mean peripapillary retinal nerve fiber layer thickness and macular thickness as identified by OCT, in patients with mild cognitive impairment and $\mathrm{AD}$ versus controls.

Thinner RNFL, GCL, and inner plexiform layer identified by OCT, associated with MR identified smaller gray-matter and white-matter volume.

Retinal nerve fiber thinning, reduced total macular and macular ganglion cell volumes identified via OCT, found to be associated with smaller MTL volumes

Both patients with severe $\mathrm{AD}$ and mild to moderate $\mathrm{AD}$ found to have evidence of significant $\mathrm{rNFL}$ thinning via OCT, compared to age matched controls.

Evidence of thinned rNFL, associated with worse cognitive function in patients without neurodegenerative disease, and associated with increased likelihood of future cognitive decline.

rNFL and retinal vessel density significantly reduced in $\mathrm{AD}$ patients compared to controls. Retinal vessel density reduction associated with impairment in some cognitive function domains.

Patients with $\mathrm{AD}$ found to have significant reductions in vessel density in superficial and deep capillary plexus compared to controls.

$\mathrm{AD}$ patients showed evidence of significant reductions in microvascular densities of the Deep retinal capillary plexus compared to matched controls, via OCT-A.

No significant difference in rNFL, GCL or macular volume on OCT in $\mathrm{AD}$ dementia versus healthy controls.

No significant difference in mean peripapillary rNFL thickness in $\mathrm{AD}$ or mild cognitively impaired patients compared to cognitively healthy patients.

While AD patients demonstrated significant decrease in rNFL thickness compared to healthy controls, there was no significant difference when compared to preperimetric glaucoma. Authors conclude changes observed on SD-OCT are non-specific. 


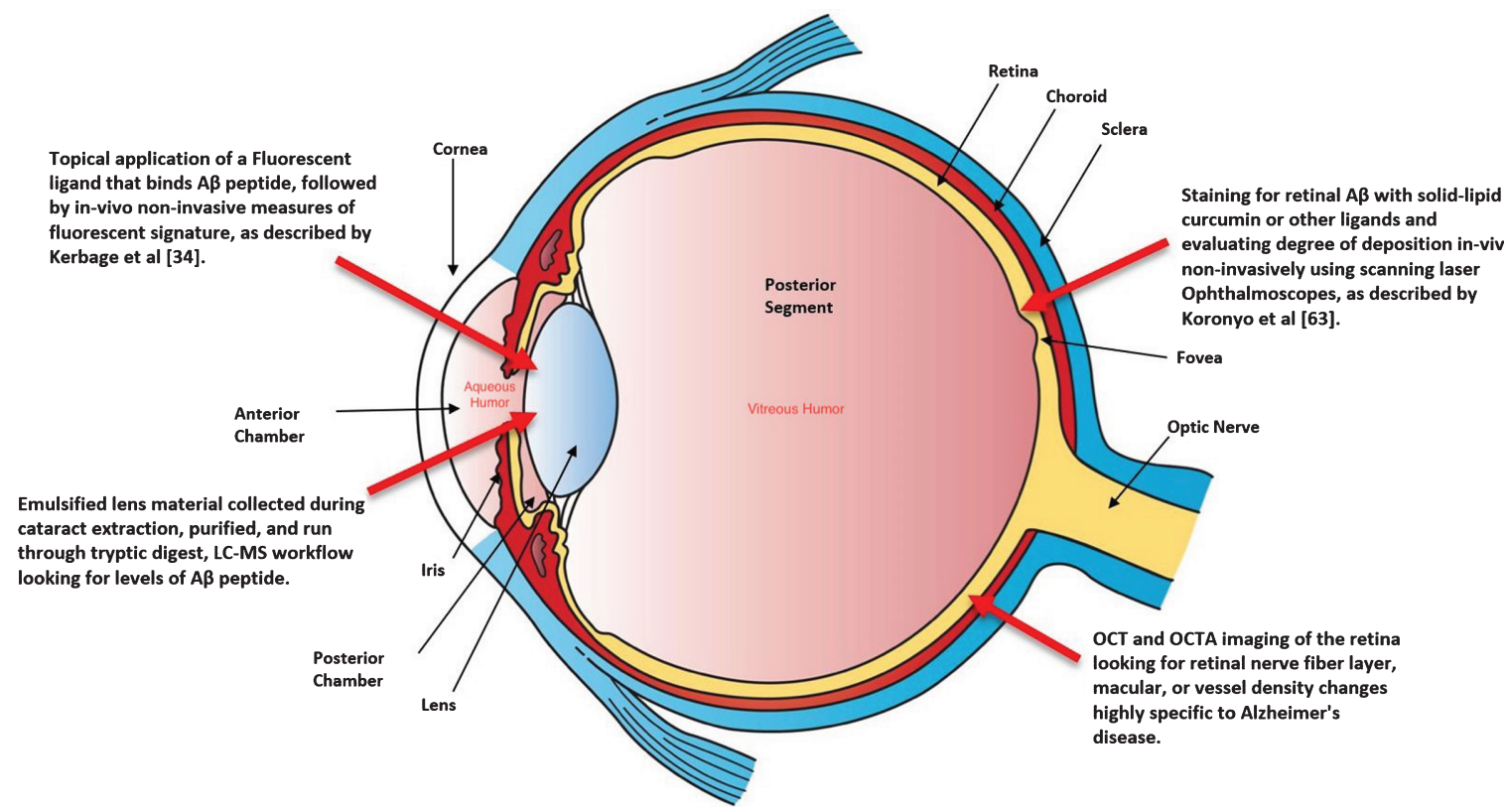

Fig. 1. Invasive and non-invasive theoretical approaches researchers have proposed for examining the eye, at all levels including the lens and retina, to look for changes specific to Alzheimer's disease [108]. This is original artwork by Holly Fischer. The authors have permission to use the figure per licensing requirements mentioned on Wikimedia common. Link to the license: (https://creativecommons.org/licenses/by/3.0/legalcode). The artwork was modified to include labels for major eye structures, and text boxes which feature theoretical descriptions of eye examination techniques to look for evidence of Alzheimer's disease.

A 2019 study by Kim et al. reports a similar reduction in thickness of the inner retinal layers in patients with severe AD compared to controls [85].

From a functional standpoint, a large prospective multicenter study based in the UK enrolled over 32,000 participants and performed baseline OCT imaging as well as a series of four cognitive tests on participants. Researchers discovered that those with rNFL thickness in the bottom $40 \%$ were nearly twice as likely to perform worse on one of the four cognitive tests, when compared to participants with relatively thicker rNFL, indicating that rNFL thickness could be used as a potential biomarker or early indicator of dementia and neurodegenerative disease [86].

In addition to retinal thinning and retinal sublayer changes, researchers have also explored potential changes in retinal vasculature in AD patients [87]. One of the earliest studies utilized laser doppler to show evidence of narrowing of venous blood column diameter and venous blood flow rate in $\mathrm{AD}$ patients compared to controls [88]. Given the relative complexity of the retinal vasculature, however, more precise imaging modalities and instrumentation were needed to highlight specific vascular changes within the retina of $\mathrm{AD}$ patients. More recent studies have thus implemented the use of OCT angiography (OCTA) to better discern the exact specific vascular changes occurring at the retina in $\mathrm{AD}$ patients [89-96]. OCTA is a relatively new technology that provides information of the retino-choroidal microvasculature in a non-invasive manner. It is an additional software enhancement to the commercially available OCT and provides supplementary vascular information similar to what can be imaged with an angiogram, but without the use of an invasive intravenous dye. It can capture images and quantify both the superficial vascular plexus (SVP) and deep vascular plexus (DVP) of the retinal microvasculature. Several studies have highlighted impairments of flow, as measured by either flow density or vessel density, of the SVP, a network of vessels that branch off of the central retinal artery [97] and supply the innermost layers of the retina, such as the rNFL and inner ganglion cell layer, in AD and cognitively impaired patients [95, 98-100]. A recent study by Yan et al. compared 37 patients with AD to 29 age matched controls and found a positive correlation between retinal vascular density and reduced rNFL thickness, measured by OCTA, in patients with mild AD [101]. Another study by Chua et al. found significantly reduced macular vessel density in both the SVP and DVP in patients with $\mathrm{AD}$, while those with MCI 
showed reduction in the SVP only [102]. Another study by Wu et al. showed similar results in the DVP in $\mathrm{AD}$ patients but a different result in MCI patients, which affected the DVP more than the SVP, from the Chua study [103].

While initial data shows promise for OCT imaging of the retina as a biomarker for early detection, there are several challenges to consider [104]. More recent studies utilizing higher resolution OCT, namely spectral domain OCT have not been able to consistently identify the same changes, or a significant difference in mean retinal thickness between $\mathrm{AD}$ and control patients as described earlier [105, 106]. Moreover, some studies have reported that a distinct retinal change unique to $\mathrm{AD}$ has not been identified, making it hard to discern $\mathrm{AD}$ related retinal thinning from other eye disease such as glaucoma and diabetic retinopathy [107]. Additionally, while several large studies and meta-analyses have supported the utility of measuring retinal cell layer thickness by OCT, OCTA is still a relatively new technology and individual studies investigating its role in $\mathrm{MCI}$ and $\mathrm{AD}$ have thus far been done in relatively small groups of patients, indicating that the use of OCTA as a tool to measure retinal vascular changes in those with MCI and $\mathrm{AD}$ is still in its early stages of investigation. Additionally, OCTA is now commercially available but not universally deployed in all practice settings primarily due to its cost and general uncertainty by clinicians if the advancement of this technology is a significant or incremental improvement in the diagnosis and management of eye disease over OCT alone, which is available universally in almost all eye physician and optometry offices. Lastly, measurements obtained by OCT and OCTA, because they are photographic tests, are unlikely to confirm AD pathology and at best can be used as a screening tool requiring further diagnostic confirmation. In short, larger, more extensive longitudinal studies are needed to identify more precise, specific patterns of retinal vascular changes, retinal thinning, and rNFL and GCL thinning changes during the course of dementia and $\mathrm{AD}$, before any of these observed structural changes could be considered as a possible novel biomarker of AD.

\section{CONCLUSION}

The goal of uncovering biomarkers in the eye that may be used for early or preclinical detection of $A D$ is possible but remains elusive. Research on the eye fluid and lens and other ocular structures to detect early signs of AD continues to be promising, particularly because it is accessible during cataract surgery, and while some early data has emerged with regard to $A \beta$ deposition in the lens and retina that are potentially unique to $\mathrm{AD}$, there is some confounding data and disagreement. Similarly, noninvasive imaging of the retina with OCT has shown promise and disagreement about distinct, identifiable AD-related changes in the retina. The more recent discovery of $\mathrm{A} \beta$, tau, and NfL in eye fluids with cognitive association is compelling but more studies are needed to replicate these findings and clarify what role they may play in early AD detection. A future consideration may be a combined approach utilizing the eye that includes noninvasive imaging of the retina as a more sensitive marker, and the detection of proteins $\mathrm{A} \beta$, tau, and $\mathrm{NfL}$ in eye fluid, lens, or retina as a more specific marker, which could resemble the combination of imaging by MRI/PET scanning and detecting proteins in CSF via lumbar puncture. What is clear is that considerably more research is needed in these particular areas of exploration. As examination and imaging techniques improve it is conceivable that larger meta-analyses and longitudinal studies exploring how the lens, retina or other parts of the eye change uniquely with dementia and $\mathrm{AD}$, could identify key patterns or findings of biomarkers for early AD diagnosis.

\section{ACKNOWLEDGMENTS}

This work was supported by: R03, NIH/NIA/ERP: 1R03AG063255-01, PI: Manju L. Subramanian MD, Project Period: 2019-2021, \$200,000. Title: Eye to Brain: Eye Biomarkers and Cognition.

\section{CONFLICT OF INTEREST}

The authors do not have any conflicts of interest to report.

\section{REFERENCES}

[1] Jameson JL, Kasper DL, Longo DL, Fauci AS, Hauser SL (2018) Harrison's principles of internal medicine, 20th edition. McGraw-Hill Education, New York.

[2] Ballard C, Gauthier S, Corbett A, Brayne C, Aarsland D, Jones E (2011) Alzheimer's disease. Lancet 377, 10191031.

[3] The Alzheimer's Association (2020) 2020 Alzheimer's disease facts and figures. Alzheimers Dement 16, 391-460.

[4] Wenk GL (2003) Neuropathologic changes in Alzheimer's disease. J Clin Psychiatry 64(Suppl 9), 7-10. 
[5] Hardy J, Allsop D (1991) Amyloid deposition as the central event in the aetiology of Alzheimer's disease. Trends Pharmacol Sci 12, 383-388.

[6] Mudher A, Lovestone S (2002) Alzheimer's disease - do tauists and baptists finally shake hands? Trends Neurosci 25, 22-26.

[7] Lee CS, Larson EB, Gibbons LE, Lee AY, McCurry SM, Bowen JD, McCormick WC, Crane PK (2019) Associations between recent and established ophthalmic conditions and risk of Alzheimer's disease. Alzheimers Dement 15, 34-41.

[8] Xu X-H, Zou J-Y, Geng W, Wang A-Y (2019) Association between glaucoma and the risk of Alzheimer's disease: A systematic review of observational studies. Acta Ophthalmol 97, 665-671.

[9] Tsilis AG, Tsilidis KK, Pelidou S-H, Kitsos G (2014) Systematic review of the association between Alzheimer's disease and chronic glaucoma. Clin Ophthalmol 8, 20952104.

[10] Lee CS, Larson EB, Gibbons LE, Latimer CS, Rose SE, Hellstern LL, Keene CD, Crane PK, Adult Changes in Thought (ACT) Study (2019) Ophthalmology-based neuropathology risk factors: Diabetic retinopathy is associated with deep microinfarcts in a community-based autopsy study. J Alzheimers Dis 68, 647-655.

[11] Klunk WE, Engler H, Nordberg A, Wang Y, Blomqvist G, Holt DP, Bergström M, Savitcheva I, Huang G-F, Estrada S, Ausén B, Debnath ML, Barletta J, Price JC, Sandell J, Lopresti BJ, Wall A, Koivisto P, Antoni G, Mathis CA (2004) Imaging brain amyloid in Alzheimer's disease with Pittsburgh Compound-B. Ann Neurol 55, 306-319.

[12] Johnson KA, Fox NC, Sperling RA, Klunk WE (2012) Brain imaging in Alzheimer disease. Cold Spring Harb Perspect Med 2, a006213.

[13] Ledig C, Schuh A, Guerrero R, Heckemann RA, Rueckert D (2018) Structural brain imaging in Alzheimer's disease and mild cognitive impairment: Biomarker analysis and shared morphometry database. Sci Rep 8, 11258 .

[14] Bateman RJ, Xiong C, Benzinger TLS, Fagan AM, Goate A, Fox NC, Marcus DS, Cairns NJ, Xie X, Blazey TM, Holtzman DM, Santacruz A, Buckles V, Oliver A, Moulder K, Aisen PS, Ghetti B, Klunk WE, McDade E, Martins RN (2012) Clinical and biomarker changes in dominantly inherited Alzheimer's disease. NEngl J Med 367, 795-804.

[15] Visser PJ, Verhey F, Knol DL, Scheltens P, Wahlund LO, Freund-Levi Y, Tsolaki M, Minthon L, Wallin AK, Hampel H, Bürger K, Pirttila T, Soininen H, Rikkert MO, Verbeek MM, Spiru L, Blennow K (2009) Prevalence and prognostic value of CSF markers of Alzheimer's disease pathology in patients with subjective cognitive impairment or mild cognitive impairment in the DESCRIPA study: A prospective cohort study. Lancet Neurol 8, 619-627.

[16] Buerger K, Ewers M, Pirttilä T, Zinkowski R, Alafuzoff I, Teipel SJ, DeBernardis J, Kerkman D, McCulloch C, Soininen H, Hampel H (2006) CSF phosphorylated tau protein correlates with neocortical neurofibrillary pathology in Alzheimer's disease. Brain 129, 3035-3041.

[17] Blennow K, Hampel H, Weiner M, Zetterberg H (2010) Cerebrospinal fluid and plasma biomarkers in Alzheimer disease. Nat Rev Neurol 6, 131-44.

[18] Gauthier SG (2005) Alzheimer's disease: The benefits of early treatment. Eur J Neurol 12, 11-16.

[19] Rasmussen J, Langerman H (2019) Alzheimer's disease why we need early diagnosis. Degener Neurol Neuromuscul Dis 9, 123-130.
[20] McKhann GM, Knopman DS, Chertkow H, Hyman BT, Jack CR, Kawas CH, Klunk WE, Koroshetz WJ, Manly JJ, Mayeux R, Mohs RC, Morris JC, Rossor MN, Scheltens P, Carrillo MC, Thies B, Weintraub S, Phelps $\mathrm{CH}$ (2011) The diagnosis of dementia due to Alzheimer's disease: Recommendations from the National Institute on Aging-Alzheimer's Association workgroups on diagnostic guidelines for Alzheimer's disease. Alzheimers Dement 7, 263-269.

[21] Jack CR, Bennett DA, Blennow K, Carrillo MC, Feldman HH, Frisoni GB, Hampel H, Jagust WJ, Johnson KA, Knopman DS, Petersen RC, Scheltens P, Sperling RA, Dubois B (2016) A/T/N: An unbiased descriptive classification scheme for Alzheimer disease biomarkers. Neurology 87, 539-547.

[22] Cummings J (2019) The role of biomarkers in Alzheimer's disease drug development. Adv Exp Med Biol 1118, 29-61.

[23] Jack CR, Bennett DA, Blennow K, Carrillo MC, Dunn B, Haeberlein SB, Holtzman DM, Jagust W, Jessen F, Karlawish J, Liu E, Molinuevo JL, Montine T, Phelps C, Rankin KP, Rowe CC, Scheltens P, Siemers E, Snyder HM, Sperling R (2018) NIA-AA Research Framework: Toward a biological definition of Alzheimer's disease. Alzheimers Dement 14, 535-562.

[24] Yanoff M, Duker JS (2008) Ophthalmology, Mosby, Edinburgh.

[25] Forrester JV, Dick AD, Mcmenamin PG, Roberts F, Pearlman E (2016) The eye: Basic sciences in practice, Saunders/Elsevier, Edinburgh; New York.

[26] Michael R, Bron AJ (2011) The ageing lens and cataract: A model of normal and pathological ageing. Philos Trans $R$ Soc Lond B Biol Sci 366, 1278-1292.

[27] Moreau KL, King JA (2012) Protein misfolding and aggregation in cataract disease and prospects for prevention. Trends Mol Med 18, 273-282.

[28] Goldstein LE, Muffat JA, Cherny RA, Moir RD, Ericsson MH, Huang X, Mavros C, Coccia JA, Faget KY, Fitch KA, Masters CL, Tanzi RE, Chylack LT, Bush AI (2003) Cytosolic beta-amyloid deposition and supranuclear cataracts in lenses from people with Alzheimer's disease. Lancet 361, 1258-1265.

[29] Moncaster JA, Pineda R, Moir RD, Lu S, Burton MA, Ghosh JG, Ericsson M, Soscia SJ, Mocofanescu A, Folkerth RD, Robb RM, Kuszak JR, Clark JI, Tanzi RE, Hunter DG, Goldstein LE (2010) Alzheimer's disease amyloidbeta links lens and brain pathology in Down syndrome. PLoS One 5, e10659.

[30] Scriver CR, Beaudet AL, Sly WS, Valle D, Stanbury JB, Wyngaarden JB, Fredrickson DS (2001) The metabolic and molecular bases of inherited disease, McGraw-Hill, Health Professions Division, New York.

[31] Weksler ME, Szabo P, Relkin NR, Reidenberg MM, Weksler BB, Coppus AMW (2013) Alzheimer's disease and Down's syndrome: Treating two paths to dementia. Autoimmun Rev 12, 670-673.

[32] Nistor M, Don M, Parekh M, Sarsoza F, Goodus M, Lopez GE, Kawas C, Leverenz J, Doran E, Lott IT, Hill M, Head E (2007) Alpha- and beta-secretase activity as a function of age and beta-amyloid in Down syndrome and normal brain. Neurobiol Aging 28, 1493-1506.

[33] Jun G, Moncaster JA, Koutras C, Seshadri S, Buros J, McKee AC, Levesque G, Wolf PA, St George-Hyslop P, Goldstein LE, Farrer LA (2012) $\delta$-Catenin is genetically and biologically associated with cortical cataract and 
future Alzheimer-related structural and functional brain changes. PloS One 7, e43728.

[34] Kerbage C, Sadowsky CH, Jennings D, Cagle GD, Hartung PD (2013) Alzheimer's disease diagnosis by detecting exogenous fluorescent signal of ligand bound to Beta amyloid in the lens of human eye: An exploratory study. Front Neurol 4, 62.

[35] Kerbage C, Sadowsky CH, Tariot PN, Agronin M, Alva G, Turner FD, Nilan D, Cameron A, Cagle GD, Hartung PD (2015) Detection of amyloid $\beta$ signature in the lens and its correlation in the brain to aid in the diagnosis of Alzheimer's disease. Am J Alzheimers Dis Other Demen 30, 738-745.

[36] Michael R, Rosandić J, Montenegro GA, Lobato E, Tresserra F, Barraquer RI, Vrensen GFJM (2013) Absence of beta-amyloid in cortical cataracts of donors with and without Alzheimer's disease. Exp Eye Res 106, 5-13.

[37] Michael R, Otto C, Lenferink A, Gelpi E, Montenegro GA, Rosandić J, Tresserra F, Barraquer RI, Vrensen GFJM (2014) Absence of amyloid-beta in lenses of Alzheimer patients: A confocal Raman microspectroscopic study. Exp Eye Res 119, 44-53.

[38] Ho C-Y, Troncoso JC, Knox D, Stark W, Eberhart CG (2013) Beta-amyloid, phospho-tau and alpha-synuclein deposits similar to those in the brain are not identified in the eyes of Alzheimer's and Parkinson's disease patients. Brain Pathol 24, 25-32.

[39] Williams EA, McGuone D, Frosch MP, Hyman BT, Laver N, Stemmer-Rachamimov A (2017) Absence of Alzheimer disease neuropathologic changes in eyes of subjects with Alzheimer disease. J Neuropathol Exp Neurol 76, 376-383.

[40] Goedert M, Spillantini MG, Crowther RA (1991) Tau proteins and neurofibrillary degeneration. Brain Pathol $\mathbf{1}$, 279-286.

[41] Chun W (2007) The role of tau phosphorylation and cleavage in neuronal cell death. Front Biosci 12, 733.

[42] Nussbaum JM, Seward ME, Bloom GS (2013) Alzheimer disease: A tale of two prions. Prion 7, 14-19.

[43] Bély M, Makovitzky J (2006) Sensitivity and specificity of Congo red staining according to Romhányi. Comparison with Puchtler's or Bennhold's methods. Acta Histochem 108, 175-180.

[44] Ji M, Arbel M, Zhang L, Freudiger CW, Hou SS, Lin D, Yang X, Bacskai BJ, Xie XS (2018) Label-free imaging of amyloid plaques in Alzheimer's disease with stimulated Raman scattering microscopy. Sci $A d v$ 4, eaat7715.

[45] Varela-Fernández R, Díaz-Tomé V, Luaces-Rodríguez A, Conde-Penedo A, García-Otero X, Luzardo-Álvarez A, Fernández-Ferreiro A, Otero-Espinar FJ (2020) Drug delivery to the posterior segment of the eye: Biopharmaceutic and pharmacokinetic considerations. Pharmaceutics 12, 269.

[46] Yu TC, Okamura R (1988) Quantitative study of characteristic aqueous humor transferrin, serum transferrin and desialized serum transferrin in aqueous humor. Jpn J Ophthalmol 32, 268-274.

[47] Lim JKH, Li Q-X, He Z, Vingrys AJ, Wong VHY, Currier N, Mullen J, Bui BV, Nguyen CTO (2016) The eye as a biomarker for Alzheimer's disease. Front Neurosci 10, 536.

[48] Inada K, Murata T, Baba H, Murata Y, Ozaki M (1988) Increase of aqueous humor proteins with aging. Jpn J Ophthalmol 32, 126-131.
[49] Janciauskiene S, Westin K, Grip O, Krakau T (2011) Detection of Alzheimer peptides and chemokines in the aqueous humor. Eur J Ophthalmol 21, 104-111.

[50] Prakasam A, Muthuswamy A, Ablonczy Z, Greig NH, Fauq A, Rao KJ, Pappolla MA, Sambamurti K (2010) Differential accumulation of secreted AbetaPP metabolites in ocular fluids. J Alzheimers Dis 20, 1243-1253.

[51] Tripathi RC, Millard CB, Tripathi BJ, Noronha A (1990) Tau fraction of transferrin is present in human aqueous humor and is not unique to cerebrospinal fluid. Exp Eye Res 50, 541-547.

[52] Yoneda S, Hara H, Hirata A, Fukushima M, Inomata Y, Tanihara H (2005) Vitreous fluid levels of betaamyloid((1-42)) and tau in patients with retinal diseases. Jpn J Ophthalmol 49, 106-108.

[53] Wright LM, Stein TD, Jun G, Chung J, McConnell K, Fiorello M, Siegel N, Ness S, Xia W, Turner KL, Subramanian ML (2019) Association of cognitive function with amyloid- $\beta$ and tau proteins in the vitreous humor. $J$ Alzheimers Dis 68, 1429-1438.

[54] Subramanian ML, Vig V, Chung J, Fiorello MG, Xia W, Zetterberg H, Blennow K, Zetterberg M, Shareef F, Siegel NH, Ness S, Jun GR, Stein TD (2020) Neurofilament light chain in the vitreous humor of the eye. Alzheimers Res Ther 12, 111.

[55] Chiu K, Chan T-F, Wu A, Leung IY-P, So K-F, Chang RC-C (2012) Neurodegeneration of the retina in mouse models of Alzheimer's disease: What can we learn from the retina? Age (Dordr) 34, 633-649.

[56] Perez SE, Lumayag S, Kovacs B, Mufson EJ, Xu S (2009) Beta-amyloid deposition and functional impairment in the retina of the APPswe/PS1DeltaE9 transgenic mouse model of Alzheimer's disease. Invest Ophthalmol Vis Sci 50, 793-800.

[57] Ning A, Cui J, To E, Ashe KH, Matsubara J (2008) Amyloid- $\beta$ deposits lead to retinal degeneration in a mouse model of Alzheimer disease. Invest Ophthalmol Vis Sci 49, 5136.

[58] Liu B, Rasool S, Yang Z, Glabe CG, Schreiber SS, Ge J, Tan Z (2009) Amyloid-peptide vaccinations reduce $\beta$ amyloid plaques but exacerbate vascular deposition and inflammation in the retina of Alzheimer's transgenic mice. Am J Pathol 175, 2099-2110.

[59] Tsai Y, Lu B, Ljubimov AV, Girman S, Ross-Cisneros FN, Sadun AA, Svendsen CN, Cohen RM, Wang S (2014) Ocular changes in TgF344-AD rat model of Alzheimer's disease. Invest Ophthalmol Vis Sci 55, 523-534.

[60] Kang J, Lemaire H-G, Unterbeck A, Salbaum JM, Masters CL, Grzeschik K-H, Multhaup G, Beyreuther K, Müller-Hill B (1987) The precursor of Alzheimer's disease amyloid A4 protein resembles a cell-surface receptor. Nature 325, 733-736.

[61] La Morgia C, Ross-Cisneros FN, Koronyo Y, Hannibal J, Gallassi R, Cantalupo G, Sambati L, Pan BX, Tozer KR, Barboni P, Provini F, Avanzini P, Carbonelli M, Pelosi A, Chui H, Liguori R, Baruzzi A, Koronyo-Hamaoui M, Sadun AA, Carelli V (2015) Melanopsin retinal ganglion cell loss in Alzheimer disease. Ann Neurol 79, 90-109.

[62] Mei X, Yang M, Zhu L, Zhou Q, Li X, Chen Z, Zou C (2020) Retinal levels of amyloid beta correlate with cerebral levels of amyloid beta in young APPswe/PS1dE9 transgenic mice before onset of Alzheimer's disease. Behav Neurol 2020, 1574816.

[63] Koronyo Y, Biggs D, Barron E, Boyer DS, Pearlman JA, Au WJ, Kile SJ, Blanco A, Fuchs D-T, Ashfaq A, 
Frautschy S, Cole GM, Miller CA, Hinton DR, Verdooner SR, Black KL, Koronyo-Hamaoui M (2017) Retinal amyloid pathology and proof-of-concept imaging trial in Alzheimer's disease. JCI Insight 2, e93621.

[64] Koronyo-Hamaoui M, Koronyo Y, Ljubimov AV, Miller CA, Ko MK, Black KL, Schwartz M, Farkas DL (2011) Identification of amyloid plaques in retinas from Alzheimer's patients and noninvasive in vivo optical imaging of retinal plaques in a mouse model. Neuroimage $\mathbf{5 4}$, S204-S217.

[65] den Haan J, Morrema THJ, Rozemuller AJ, Bouwman FH, Hoozemans JJM (2018) Different curcumin forms selectively bind fibrillar amyloid beta in post mortem Alzheimer's disease brains: Implications for in-vivo diagnostics. Acta Neuropathol Commun 6, 75.

[66] Jiang J, Wang H, Li W, Cao X, Li C (2016) Amyloid plaques in retina for diagnosis in Alzheimer's patients: A meta-analysis. Front Aging Neurosci 8, 267.

[67] Blanks JC, Hinton DR, Sadun AA, Miller CA (1989) Retinal ganglion cell degeneration in Alzheimer's disease. Brain Res 501, 364-372.

[68] Sadun AA, Bassi CJ (1990) Optic nerve damage in Alzheimer's disease. Ophthalmology 97, 9-17.

[69] Asanad S, Ross-Cisneros FN, Nassisi M, Barron E, Karanjia R, Sadun AA (2019) The Retina in Alzheimer's disease: Histomorphometric analysis of an ophthalmologic biomarker. Invest Ophthalmol Vis Sci 60, 1491-1500.

[70] Blanks JC, Schmidt SY, Torigoe Y, Porrello KV, Hinton DR, Blanks RH (1996) Retinal pathology in Alzheimer's disease. II. Regional neuron loss and glial changes in GCL. Neurobiol Aging 17, 385-395.

[71] Oktem EO, Derle E, Kibaroglu S, Oktem C, Akkoyun I, Can U (2015) The relationship between the degree of cognitive impairment and retinal nerve fiber layer thickness. Neurol Sci 36, 1141-1146.

[72] Cheung CY, Ong YT, Hilal S, Ikram MK, Low S, Ong YL, Venketasubramanian N, Yap P, Seow D, Chen CLH, Wong TY (2015) Retinal ganglion cell analysis using high-definition optical coherence tomography in patients with mild cognitive impairment and Alzheimer's disease. $J$ Alzheimers Dis 45, 45-56.

[73] Cunha LP, Lopes LC, Costa-Cunha LVF, Costa CF, Pires LA, Almeida ALM, Monteiro MLR (2016) Macular thickness measurements with frequency domain-OCT for quantification of retinal neural loss and its correlation with cognitive impairment in Alzheimer's disease. PLoS One 11, e0153830.

[74] Garcia-Martin ES, Rojas B, Ramirez AI, de Hoz R, Salazar JJ, Yubero R, Gil P, Triviño A, Ramirez JM (2014) Macular thickness as a potential biomarker of mild Alzheimer's disease. Ophthalmology 121, 1149-1151.e3.

[75] den Haan J, Janssen SF, van de Kreeke JA, Scheltens P, Verbraak FD, Bouwman FH (2018) Retinal thickness correlates with parietal cortical atrophy in early-onset Alzheimer's disease and controls. Alzheimers Dement (Amst) 10, 49-55.

[76] Garcia-Martin E, Bambo MP, Marques ML, Satue M, Otin S, Larrosa JM, Polo V, Pablo LE (2016) Ganglion cell layer measurements correlate with disease severity in patients with Alzheimer's disease. Acta Ophthalmol 94, e454-459.

[77] Cunha JP, Proença R, Dias-Santos A, Almeida R, Águas H, Alves M, Papoila AL, Louro C, Castanheira-Dinis A (2017) OCT in Alzheimer's disease: Thinning of the RNFL and superior hemiretina. Graefes Arch Clin Exp Ophthalmol 255, 1827-1835.
[78] Kwon JY, Yang JH, Han JS, Kim DG (2017) Analysis of the retinal nerve fiber layer thickness in Alzheimer disease and mild cognitive impairment. Korean J Ophthalmol 31, 548-556.

[79] Liu S, Ong Y-T, Hilal S, Loke YM, Wong TY, Chen CLH, Cheung CY, Zhou J (2016) The association between retinal neuronal layer and brain structure is disrupted in patients with cognitive impairment and Alzheimer's disease. J Alzheimers Dis 54, 585-595.

[80] Cunha JP, Proença R, Dias-Santos A, Melancia D, Almeida R, Águas H, Santos BO, Alves M, Ferreira J, Papoila AL, Louro C, Castanheira-Dinis A (2017) Choroidal thinning: Alzheimer's disease and aging. Alzheimers Dement (Amst) 8, 11-17.

[81] Trebbastoni A, Marcelli M, Mallone F, D'Antonio F, Imbriano L, Campanelli A, de Lena C, Gharbiya M (2017) Attenuation of choroidal thickness in patients with Alzheimer disease: Evidence from an Italian prospective study. Alzheimer Dis Assoc Disord 31, 128-134.

[82] den Haan J, Verbraak FD, Visser PJ, Bouwman FH (2017) Retinal thickness in Alzheimer's disease: A systematic review and meta-analysis. Alzheimers Dement (Amst) 6, 162-170.

[83] Mutlu U, Bonnemaijer PWM, Ikram MA, Colijn JM, Cremers LGM, Buitendijk GHS, Vingerling JR, Niessen WJ, Vernooij MW, Klaver CCW, Ikram MK (2017) Retinal neurodegeneration and brain MRI markers: The Rotterdam Study. Neurobiol Aging 60, 183-191.

[84] Casaletto KB, Ward ME, Baker NS, Bettcher BM, Gelfand JM, Li Y, Chen R, Dutt S, Miller B, Kramer JH, Green AJ (2017) Retinal thinning is uniquely associated with medial temporal lobe atrophy in neurologically normal older adults. Neurobiol Aging 51, 141-147.

[85] Kim J-I, Kang B-H (2019) Decreased retinal thickness in patients with Alzheimer's disease is correlated with disease severity. PLoS One 14, e0224180.

[86] Ko F, Muthy ZA, Gallacher J, Sudlow C, Rees G, Yang Q, Keane PA, Petzold A, Khaw PT, Reisman C, Strouthidis NG, Foster PJ, Patel PJ, UK Biobank Eye \& Vision Consortium (2018) Association of retinal nerve fiber layer thinning with current and future cognitive decline: A study using optical coherence tomography. JAMA Neurol 75, 1198-1205.

[87] Patton N, Aslam T, MacGillivray T, Pattie A, Deary IJ, Dhillon B (2005) Retinal vascular image analysis as a potential screening tool for cerebrovascular disease: A rationale based on homology between cerebral and retinal microvasculatures. J Anat 206, 319-348.

[88] Berisha F, Feke GT, Trempe CL, McMeel JW, Schepens CL (2007) Retinal abnormalities in early Alzheimer's disease. Invest Ophthalmol Vis Sci 48, 2285-2289.

[89] O'Bryhim BE, Apte RS, Kung N, Coble D, Stavern GPV (2018) Association of preclinical Alzheimer disease with optical coherence tomographic angiography findings. JAMA Ophthalmol 136, 1242-1248.

[90] Querques G, Borrelli E, Sacconi R, De Vitis L, Leocani L, Santangelo R, Magnani G, Comi G, Bandello F (2019) Functional and morphological changes of the retinal vessels in Alzheimer's disease and mild cognitive impairment. Sci Rep 9, 63.

[91] Mardin CY, Hosari S (2019) Optical coherence tomography angiography in neuronal diseases: Preliminary findings. Ophthalmologe 116, 714-721.

[92] van de Kreeke JA, Nguyen H-T, Konijnenberg E, Tomassen J, den Braber A, Ten Kate M, Yaqub M, van 
Berckel B, Lammertsma AA, Boomsma DI, Tan SH, Verbraak F, Visser PJ (2020) Optical coherence tomography angiography in preclinical Alzheimer's disease. $\mathrm{Br} \mathrm{J} \mathrm{Oph-}$ thalmol 104, 157-161.

[93] Yoon SP, Grewal DS, Thompson AC, Polascik BW, Dunn C, Burke JR, Fekrat S (2019) Retinal microvascular and neurodegenerative changes in Alzheimer's disease and mild cognitive impairment compared with control participants. Ophthalmol Retina 3, 489-499.

[94] Zabel P, Kaluzny JJ, Wilkosc-Debczynska M, GebskaToloczko M, Suwala K, Zabel K, Zaron A, Kucharski R, Araszkiewicz A (2019) Comparison of retinal microvasculature in patients with Alzheimer's disease and primary open-angle glaucoma by optical coherence tomography angiography. Invest Ophthalmol Vis Sci 60, 3447-3455.

[95] Grewal DS, Polascik BW, Hoffmeyer GC, Fekrat S (2018) Assessment of differences in retinal microvasculature using OCT angiography in Alzheimer's disease: A twin discordance report. Ophthalmic Surg Lasers Imaging Retina 49, 440-444.

[96] Yoon SP, Thompson AC, Polascik BW, Calixte C, Burke JR, Petrella JR, Grewal DS, Fekrat S (2019) Correlation of OCTA and volumetric MRI in mild cognitive impairment and Alzheimer's disease. Ophthalmic Surg Lasers Imaging Retina 50, 709-718.

[97] Campbell JP, Zhang M, Hwang TS, Bailey ST, Wilson DJ, Jia Y, Huang D (2017) Detailed vascular anatomy of the human retina by projection-resolved optical coherence tomography angiography. Sci Rep 7, 42201.

[98] Lahme L, Esser EL, Mihailovic N, Schubert F, Lauermann J, Johnen A, Eter N, Duning T, Alnawaiseh M (2018) Evaluation of ocular perfusion in Alzheimer's disease using optical coherence tomography angiography. J Alzheimers Dis 66, 1745-1752.

[99] Jiang H, Wei Y, Shi Y, Wright CB, Sun X, Gregori G, Zheng F, Vanner EA, Lam BL, Rundek T, Wang J (2018) Altered macular microvasculature in mild cognitive impairment and Alzheimer disease. J Neuroophthalmol 38, 292-298.

[100] Zhang YS, Zhou N, Knoll BM, Samra S, Ward MR, Weintraub S, Fawzi AA (2019) Parafoveal vessel loss and correlation between peripapillary vessel density and cognitive performance in amnestic mild cognitive impairment and early Alzheimer's disease on optical coherence tomography angiography. PLoS One 14, e 0214685.
[101] Yan Y, Wu X, Wang X, Geng Z, Wang L, Xiao G, Wu Y, Zhou S, Wei L, Tian Y, Wang K (2021) The retinal vessel density can reflect cognitive function in patients with Alzheimer's disease: Evidence from optical coherence tomography angiography. J Alzheimers Dis 79, 13071316.

[102] Chua J, Hu Q, Ke M, Tan B, Hong J, Yao X, Hilal S, Venketasubramanian N, Garhöfer G, Cheung CY, Wong TY, Chen CL-H, Schmetterer L (2020) Retinal microvasculature dysfunction is associated with Alzheimer's disease and mild cognitive impairment. Alzheimers Res Ther 12, 161.

[103] Wu J, Zhang X, Azhati G, Li T, Xu G, Liu F (2020) Retinal microvascular attenuation in mental cognitive impairment and Alzheimer's disease by optical coherence tomography angiography. Acta Ophthalmol 98, e781-e787.

[104] Ngolab J, Honma P, Rissman RA (2019) Reflections on the utility of the retina as a biomarker for Alzheimer's disease: A literature review. Neurol Ther 8, 57-72.

[105] Pillai JA, Bermel R, Bonner-Jackson A, Rae-Grant A, Fernandez H, Bena J, Jones SE, Ehlers JP, Leverenz JB (2016) Retinal nerve fiber layer thinning in Alzheimer's disease: A case-control study in comparison to normal aging, Parkinson's disease, and non-Alzheimer's dementia. Am J Alzheimers Dis Other Demen 31, 430-436.

[106] Sánchez D, Castilla-Marti M, Rodríguez-Gómez O, Valero S, Piferrer A, Martínez G, Martínez J, Serra J, MorenoGrau S, Hernández-Olasagarre B, De Rojas I, Hernández I, Abdelnour C, Rosende-Roca M, Vargas L, Mauleón A, Santos-Santos MA, Alegret M, Ortega G, Espinosa A (2018) Usefulness of peripapillary nerve fiber layer thickness assessed by optical coherence tomography as a biomarker for Alzheimer's disease. Sci Rep 8, 16345.

[107] Zabel P, Kałużny JJ, Wiłkość-Dębczyńska M, GębskaTołoczko M, Suwała K, Kucharski R, Araszkiewicz A (2019) Peripapillary retinal nerve fiber layer thickness in patients with Alzheimer's disease: A comparison of eyes of patients with Alzheimer's disease, primary open-angle glaucoma, and preperimetric glaucoma and healthy controls. Med Sci Monit 25, 1001-1008.

[108] Fischer H (2013) Three Main Layers of the Eye. 